\title{
Cohort study of cardiovascular risk in asymptomatic young adults: subclinical atherosclerosis and coronary calcium score
}

\author{
SADI POLETTO ${ }^{1}$, PAULO R. SCHVARTZMAN ${ }^{2}$, NEIDE M. BRUSCATO ${ }^{3}$ and EMILIO MORIGUCHI ${ }^{4}$ \\ ${ }^{1}$ Programa de Pós-Graduação em Saúde Coletiva, Universidade do Vale do Rio dos Sinos/UNISINOS, Rua \\ Saldanha Marinho, 435, Sala 809, Centro, Galeria Solar, 95700-080 Bento Gonçalves, RS, Brazil \\ ${ }^{2}$ Hospital Tacchini, Rua Carlos Trein Filho, 909, Auxiliadora, 90450-120 Porto Alegre, RS, Brazil \\ ${ }^{3}$ Projeto Veranópolis Estudos em Envelhecimento, Longevidade e Qualidade de Vida, Associação Veranense de Assistência em \\ Saúde/AVAES, Hospital São Pelegrino Lazziozi, Rua Saul Irineu Farina, 160, São Pelegrino, 95330-000 Veranópolis, RS, Brazil \\ ${ }^{4}$ Programa de Pós-Graduação em Saúde Coletiva, Universidade do Vale do Rio dos Sinos/ \\ UNISINOS, Av. Unisinos, 950, Cristo Rei, 93022-750 São Leopoldo, RS, Brazil
}

Manuscript received on January 16, 2018; accepted for publication on March 23, 2018

\begin{abstract}
Coronary artery calcification is an early marker of subclinical atherosclerosis, but little research has been done in asymptomatic individuals under 45 years. In this cohort study with 17 years of follow-up, 155 participants were assessed in 2016 with a coronary calcium score for the association with cardiovascular risk factors. During follow-up, there was a significant increase in anthropometric measurements, cholesterol and fractions, and diastolic pressure. Participants who gained $1 \mathrm{~cm}$ in waist circumference had a mean reduction of $0.36 \mathrm{mg} / \mathrm{dL}$ in HDL-cholesterol and those who gained $1 \mathrm{~kg} / \mathrm{m}^{2}$ in body mass index had a reduction of $0.72 \mathrm{mg} / \mathrm{dL}$ in HDL-cholesterol. Married participants had a $4.78 \mathrm{mg} / \mathrm{dL}$ reduction in HDLcholesterol levels compared to singles. There was an increase of $2.09 \mathrm{mg} / \mathrm{dL}$ in HDL-cholesterol at each higher level of self-perceived health. One single case, a 32-year-old male, smoker, sedentary individual with a family history of cardiovascular disease, presented coronary calcification $(0.6 \%)$. His HDL-cholesterol was reduced by $43.4 \%$, with levels of less than $25 \mathrm{mg} / \mathrm{dL}$ at the time of coronary calcium scoring. Our findings may prompt broader studies of populations under 35 years with HDL-C levels below $25 \mathrm{mg} / \mathrm{dL}$ and family histories of cardiovascular disease, associated with obesity, sedentary lifestyle and smoking.
\end{abstract}

Key words: cardiovascular disease, coronary calcium score, subclinical atherosclerosis, cohort study.

\section{INTRODUCTION}

Cardiovascular diseases stand out as the current leading cause of death worldwide. Coronary artery disease (CAD) and its thrombotic complications

Correspondence to: Sadi Poletto

E-mails: sadi@poletto.med.br

adipoletto@gmail.com are the main cause of morbidity and mortality in developed countries (Go et al. 2014). CAD is a multifactorial disease, and identifying people at high risk for this event is extremely important because certain drugs can significantly reduce clinical events and mortality (Meneghelo et al. 2003).

An acute coronary event occurs as the first manifestation of atherosclerotic disease in 
approximately half of affected individuals (Xavier et al. 2013). Guidelines for primary prevention of cardiovascular disease state that cardiovascular risk prediction helps to define the prognosis and sets treatment goals to motivate patients to adhere to lifestyle changes (Sara et al. 2014). In this respect, the quantification of coronary artery impairment using imaging methods, such as coronary artery calcium (CAC) scanning, is an independent predictor of events and useful for risk reclassification in asymptomatic subjects, since there is evidence that the atherosclerotic plaque burden correlates with the risk of coronary events (Meneghelo et al. 2003). Also, CAC quantification may alter clinical conduct, especially regarding intermediate risk asymptomatic patients and low risk patients with a family history of early CAD (Sara et al. 2014).

The MESA study, a population-based cohort study assessing the risk of coronary heart disease in individuals without known cardiovascular disease, has shown that addition of the CAC score to a prediction model based on traditional risk factors can significantly improve the prediction of future coronary events (Polonsky et al. 2010). The CARDIA study, a prospective longitudinal study of cardiovascular risk factors in young adults, has shown that, when the CAC score is added to models, the risk stratification of cardiovascular events by global indices can improve event prediction (Lee et al. 2007). Also, compared with other stratification tools for detecting subclinical atherosclerosis, the CAC score has been demonstrated as one of the most accurate tools and has added prognostic value to traditional Framingham risk factors, C-reactive protein (CRP) and intimal-medial thickness (IMT) in spite of differences in the prevalence of coronary calcification among different ethnic groups (Sara et al. 2014).

Although coronary artery calcification is considered an early marker of subclinical atherosclerosis, little research has been done in asymptomatic individuals under 45 years. The present study was therefore designed to characterize the association between the CAC score and the evolution of cardiovascular risk factors from adolescence to young adulthood in a 17-year follow-up period.

\section{MATERIALS AND METHODS}

\section{POPULATION AND STUDY DESIGN}

The baseline of this prospective cohort study was in 1999. The base population consisted of children and adolescents between 10 and 18 years of age residing in the municipality of Veranópolis, Rio Grande do Sul (which includes urban and rural areas), and regularly enrolled in school in 1999. At that time, the municipality had a population of 19,440 inhabitants, including 3,438 adolescents between 10 and 18 years of age. Baseline exclusion criteria were previous chronic disease (e.g. heart disease, thyroid disease, liver disease, nephropathy, and coagulopathy) or acute disease (e.g. infectious and contagious diseases), continued use of medication (e.g. oral anticoagulants, contraceptives, and systemic corticosteroids), or pregnancy (Pitrez Filho 2000).

Participants were recruited among elementary, middle and high school students attending local municipal, state-run or private schools. For a representative selection of participants, the 29 elementary/middle schools and 3 high schools located in the 10 urban and 8 rural census tracts in the municipality, as previously determined by the Brazilian Institute of Geography and Statistics, were included. School directors received an estimate of the number of children and adolescents to be recruited for the study and were instructed to keep an approximately equal proportion of males and females in the selected sample. For the random selection of participants, all students \#10 in class attendance sheets were screened for eligibility, and if eligible, they were invited to participate 
in the study. Then, students were approached successively (students \#11, \#12,\#13, etc.) until enough participants had been recruited to achieve the required sample size at each school. In schools with a very small number of students, at least one participant should be selected (Pitrez Filho 2000).

After the baseline collection in 1999, the participants were followed-up with two more collections (2006 and 2016), as shown in Figure 1. Baseline and follow-up evaluations included interview with the participants and their parents, family history taking, clinical examination, blood collection, and anthropometric measurements (Pitrez Filho 2000, Santana et al. 2012). CAC measurement using coronary artery tomography was included in the 2016 follow-up evaluation. For this reason, pregnant participants were excluded from this round of data collection due to the risk of radiation exposure.

This study was approved by the Research Ethics Committee of Universidade do Vale do Rio dos Sinos (UNISINOS), approval number 180/2015. Written informed consent was obtained from the participants prior to inclusion in the study.

SAMPLE SIZE CALCULATION

The sample size was calculated using WinPEPI, version 11.43 . To detect a difference of $25 \%$ in the reduction in high-density lipoprotein cholesterol (HDL-C) levels between the groups (presence or absence of calcification), with a significance level of $5 \%$ and power of $90 \%$, a minimum sample size of 154 individuals was necessary. The reason for this is that lower HDL-C levels are a potent predictor of the risk of future coronary events: with every $25 \%$ reduction, the risk of cardiovascular events doubles (Castelli 1988).

\section{PROCEDURES FOR OBTAINING THE CAC SCORE}

The CAC scores were measured by computed tomography of the coronary arteries at the
Bartholomeu Tacchini Association's Diagnostic Imaging Center (Bento Gonçalves, Rio Grande do Sul, Brazil). Multi-detector computed tomography (MDCT) was performed with a Somatom Sensation Multislice 10 (serial number 57189, ANVISA registration number: 10234230150) with a constant-potential three-phase generator.

No invasive procedures are involved in the examination; the only requirements are to wear a hospital gown and remove any metal accessories. After lying supine on the tomography table, the electrocardiographic monitoring electrodes are placed to synchronize image capture and heart rate observation during the examination. The table was remotely controlled by the operator, who recorded, on 40 channels, an average of 136 cardiac image slices, which also included the coronary arteries.

Axial chest images were captured in a window from the aortic root to the apex of the heart. Forty contiguous transverse images $2.5-3.0 \mathrm{~mm}$ thick were captured at the moment of diastole, with a 15 -second inspiratory pause according to Agatston's protocol (Agatston et al. 1990). The test was performed without the use of medications or contrasts and without specific preparation. The test's radiation level is 0.7 to $1 \mathrm{mSv} /$ year, which is lower than that of mammography (1.0 mSv/year).

The results were interpreted with the CACSCORE program. The CAC score was obtained from calcification fragments measured using the calcification index; age correction was performed and the results were classified according to degree of calcification: for a CAC score of zero, there is no calcification; for a score from 1 to 10 , minimal calcification; for a score from 11 to 100 , light calcification; for a score from 101 to 400 , moderate calcification; for a score from 401 to 1000 , severe calcification; and for a score $>1000$, very severe calcification (Azevedo et al. 2012). 


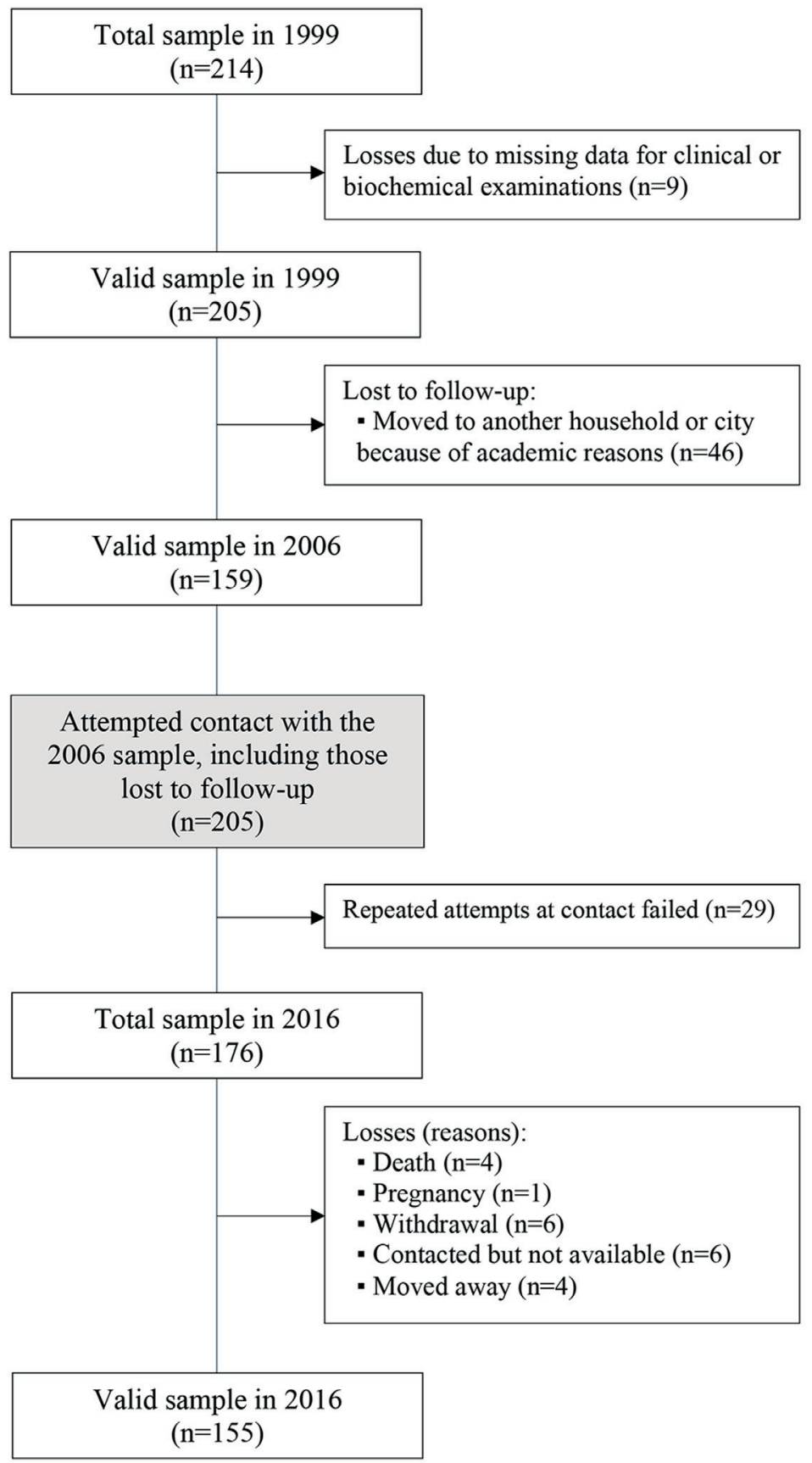

Figure 1 - Flowchart of study design with information on losses in 2016.

DATA ANALYSIS

Quantitative variables were expressed as mean and standard deviation, and categorical variables were expressed as absolute and relative frequencies. Student's t-test for paired samples was used to compare the parameters over time. A multivariate linear regression model was constructed to examine factors related to the variation of HDL-C levels and control for confounding factors. Variables with a p-value $<0.20$ in the bivariate analysis were included in the multivariate model. Only variables that presented a $\mathrm{p}$-value $<0.10$ remained in the final model. The variance inflation factor (VIF) 
was used to investigate the potential of collinearity among independent variables. VIF values above 10 indicate high collinearity, while values above 5 should also be treated with care (Hair et al. 1998). The significance level was set at 5\%. All analyses were performed using SPSS, version 21.0.

\section{RESULTS}

The final sample consisted of 155 cohort participants submitted to coronary tomography. The mean age in the 2016 evaluation was 29.9 years $( \pm 2.8$; min. 27, max. 36). Other sample characteristics are shown in Table I.

Over the follow-up period, there were significant increases in body mass index (BMI), waist circumference (WC), total cholesterol, HDL-C, triglycerides, and diastolic blood pressure (DBP), but significant reductions in blood glucose and systolic blood pressure (SBP) (Table II).

Among the CAC scores, there was one case of coronary artery calcification (12.7 AU). The 1999, 2006 and 2016 HDL-C values for this male participant were $41 \mathrm{mg} / \mathrm{dL}, 33 \mathrm{mg} / \mathrm{dL}$ and $23.2 \mathrm{mg} / \mathrm{dL}$, respectively. The latter value was the lowest found among all study participants in 2016, representing a $43.4 \%$ reduction in HDL-C levels. The individual also had a family history of early cardiovascular disease and was sedentary, obese and a smoker; his BMI and WC increased approximately $18 \%$ and $29 \%$, respectively, between 1999 and 2016.

The CAC score results for the above-mentioned participant are described in Table III. Despite a slight degree of observed calcification, he was above the 75 th percentile for age and sex. Figure 2 shows images from this participant's coronary tomography examination.

Since only one case of altered CAC was detected, associations between change in HDL-C levels and the study variables were investigated. Those with $\mathrm{p}$-values $<0.20$ were inserted into a
TABLE I

Characterization of cohort participants who underwent coronary artery tomography in 2016.

\begin{tabular}{lcc}
\hline Variables (n=155) & $\begin{array}{c}\text { Absolute } \\
\text { frequency }\end{array}$ & $\begin{array}{c}\text { Relative } \\
\text { frequency (\%) }\end{array}$ \\
\hline Demographic data & & \\
\hline Sex & 80 & 51.6 \\
Men & 75 & 48.4 \\
Women & 76 & \\
\hline Marital status & 1 & 49.0 \\
Married & 78 & 0.6 \\
Divorced & 50.3 \\
Single & 144 & 92.9 \\
Race & 3 & 1.9 \\
White & 8 & 5.2 \\
Black & & \\
Mixed race & &
\end{tabular}

Socioeconomic data

Education

\begin{tabular}{lcc}
5 to 8 years of schooling & 3 & 1.9 \\
9 to 12 years of schooling & 44 & 28.4 \\
$\begin{array}{l}13 \text { or more years of } \\
\text { schooling }\end{array}$ & 108 & 69.7 \\
\hline $\begin{array}{l}\text { Income } \\
1 \text { to } 5 \text { x minimum wage }\end{array}$ & 128 & 82.6 \\
6 to 10 x minimum wage & 21 & 13.5 \\
$\begin{array}{l}\text { more than } 10 \text { x minimum } \\
\text { wage }\end{array}$ & 6 & 3.9
\end{tabular}

Behavioral data

Physical activity

Yes $76 \quad 49.0$

$\begin{array}{lll}\text { No } & 79 & 51.0\end{array}$

Smoking

Nonsmoker $\quad 132$

$\begin{array}{lll}\text { Ex-smoker } & 13 & 8.4\end{array}$

Smoker $\quad 10 \quad 6.4$

Self-reported health

$\begin{array}{lll}\text { Excellent } & 42 & 27.1\end{array}$

$\begin{array}{lll}\text { Very good } & 47 & 30.3\end{array}$

$\begin{array}{lll}\text { Good } & 60 & 38.7\end{array}$

$\begin{array}{lll}\text { Normal } & 6 & 3.9\end{array}$

Currently on medication

$\begin{array}{lll}\text { Yes } & 80 & 51.6\end{array}$

$\begin{array}{lll}\text { No } & 75 & 48.4\end{array}$ 
TABLE II

Variation in the cohort's anthropometric and biochemical data during the follow-up period (1999-2016).

\begin{tabular}{|c|c|c|c|c|}
\hline Variables & $\begin{array}{c}1999 \\
\text { Mean } \pm \text { SD }\end{array}$ & $\begin{array}{c}2016 \\
\text { Mean } \pm \text { SD }\end{array}$ & $\begin{array}{c}\text { Difference } \\
(95 \% \mathrm{CI})\end{array}$ & $\mathbf{p}$ \\
\hline BMI $\left(\mathrm{kg} / \mathrm{m}^{2}\right)$ & $21.5 \pm 4.0$ & $26.2 \pm 4.9$ & $4.6(4.0$ to 5.3$)$ & $<0.001$ \\
\hline $\mathrm{WC}(\mathrm{cm})$ & $72.8 \pm 11.0$ & $88.6 \pm 12.3$ & $15.8(14.2$ to 17.4$)$ & $<0.001$ \\
\hline COL-T (mg/dL) & $174.9 \pm 28.0$ & $189.2 \pm 33.9$ & $14.3(8.9$ to 19.8$)$ & $<0.001$ \\
\hline HDL-C (mg/dL) & $46.0 \pm 7.6$ & $54.4 \pm 14.3$ & $8.4(6.3$ to 10.5$)$ & $<0.001$ \\
\hline LDL-C (mg/dL) & $111.9 \pm 24.5$ & $114.3 \pm 29.3$ & $2.4(-2.3$ to 7.2$)$ & 0.316 \\
\hline $\mathrm{TG}(\mathrm{mg} / \mathrm{dL})$ & $85.2 \pm 38.8$ & $102.4 \pm 54.9$ & $17.2(7.2$ to 27.1$)$ & 0.001 \\
\hline $\mathrm{SBP}(\mathrm{mmHg})$ & $131.2 \pm 17.9$ & $120.2 \pm 13.3$ & $-10.9(-13.8$ to -8.0$)$ & $<0.001$ \\
\hline $\mathrm{DBP}(\mathrm{mmHg})$ & $66.4 \pm 10.7$ & $75.3 \pm 8.9$ & $8.9(6.9$ to 10.8$)$ & $<0.001$ \\
\hline GLY (mg/dL) & $86.9 \pm 8.7$ & $84.2 \pm 8.9$ & $-2.7(-4.3$ to 1.1$)$ & 0.001 \\
\hline
\end{tabular}

BMI, body mass index; WC, waist circumference; COL-T, total cholesterol; HDL-C, high-density lipoprotein cholesterol; LDL-C, low-density lipoprotein cholesterol; TG, triglycerides; SBP, systolic blood pressure; DBP, diastolic blood pressure; GLY, fasting glycemia.

TABLE III

CAC score results for the participant with coronary artery calcification.

\begin{tabular}{|c|c|c|c|c|}
\hline \multicolumn{5}{|c|}{ Threshold = $130 \mathrm{HU}\left(102.3 \mathrm{mg} / \mathrm{cm}^{3} \mathrm{CaHA}\right)$} \\
\hline Artery & Number of lesions (1) & Volume $\left(\mathrm{mm}^{3}\right)(3)$ & Equiv. mass (mg of CaHA) (4) & Calcium score (2) \\
\hline LM & 0 & 0.0 & 0.00 & 0.0 \\
\hline LAD & 1 & 3.5 & 0.90 & 2.7 \\
\hline $\mathrm{CX}$ & 3 & 14.7 & 2.34 & 10.0 \\
\hline RDA & 0 & 0.0 & 0.00 & 0.0 \\
\hline Total & 4 & 18.2 & 3.24 & 12.7 \\
\hline
\end{tabular}

(1) Volume-based lesion; (3) Isotropic interpolated volume; (4) Calibration factor: 0.787; (2) Equivalent Agatston score CAC, coronary artery calcium; CaHA, calcium hydroxyapatite; LM, left main coronary; LAD, left anterior descending; CX, coronary circumflex; RDA, right descending artery.
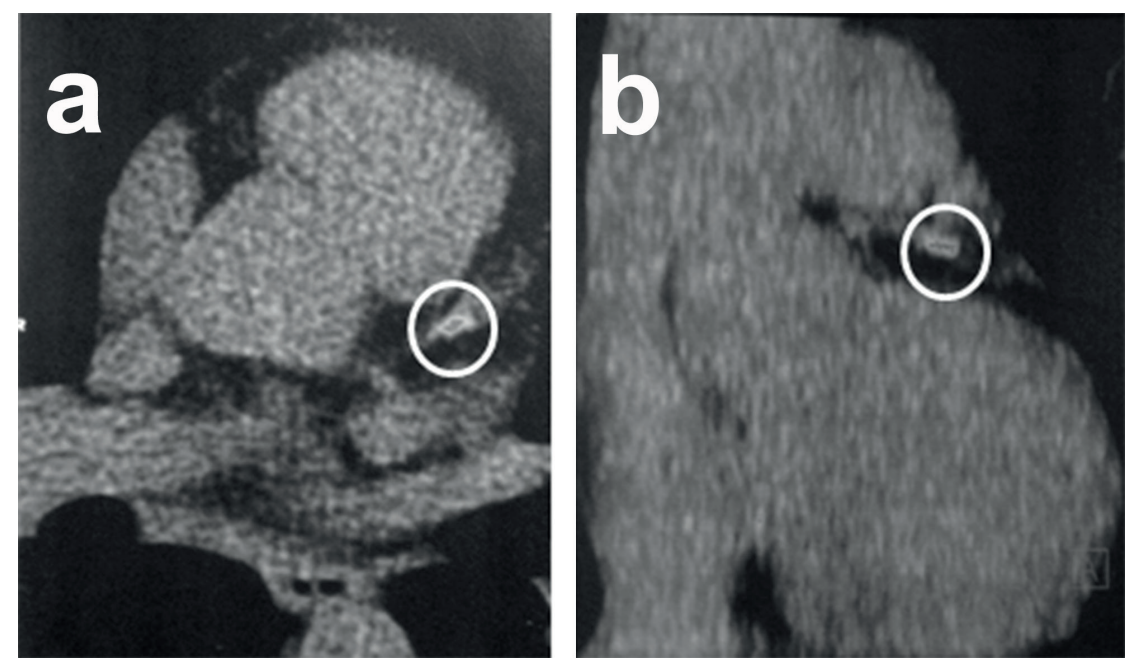

Figure 2 - Tomographic images of the coronary arteries of the participant with coronary artery calcification. a) coronary circumflex artery b) left anterior descending artery. 
multivariate model. All VIF values were below 5, indicating no evidence of multicollinearity. The variables that remained significant after adjustment are presented in Table IV. Male HDL-C levels were $6.44 \mathrm{mg} / \mathrm{dL}$ lower than those of female participants. Participants who increased $1 \mathrm{~cm}$ in $\mathrm{WC}$ had a mean reduction of $0.36 \mathrm{mg} / \mathrm{dL}$ in HDL-C, and those who increased $1 \mathrm{~kg} / \mathrm{m}^{2}$ in BMI had a reduction of $0.72 \mathrm{mg} / \mathrm{dL}$ in HDL-C. The HDL-C level of married participants was $4.78 \mathrm{mg} / \mathrm{dL}$ lower than that of singles, and there was an HDL-C increase of $2.09 \mathrm{mg} / \mathrm{dL}$ at each higher level of self-reported health. Among factors significantly associated with variation in HDL-C levels (higher beta values), WC was the strongest, followed by sex.

\section{DISCUSSION}

Detectable CAC is an important marker of coronary atherosclerosis, as even mild CAC is associated with increased cardiovascular events (Alluri et al. 2015). Over a 17-year period, there was only one case of nonzero CAC score (12.7 AU) in our cohort of asymptomatic young adults under 35 years. Despite a slight degree of observed calcification, this participant was above the 75th percentile for age and sex. When the calculations were adjusted to the Brazilian Society of Cardiology/Brazilian

\section{TABLE IV}

Multivariate linear regression analysis of factors associated with altered HDL-C levels.

\begin{tabular}{cccc}
\hline \multirow{2}{*}{ Variables } & \multicolumn{3}{c}{ Variation in HDL-C levels $(\Delta$ HDL $)$} \\
\cline { 2 - 4 } & $\mathbf{b}(\mathbf{9 5 \%} \mathbf{C I})$ & Beta & $\mathbf{p}$ \\
\hline Male & $-6.4(-10.8$ to -2.1$)$ & -0.26 & 0.004 \\
$\begin{array}{c}\text { Variation in } \\
\text { WC }(\Delta \text { WC) }\end{array}$ & $-0.3(-0.5$ to -0.1$)$ & -0.28 & 0.001 \\
$\begin{array}{c}\text { Variation in } \\
\text { BMI }(\Delta \text { BMI) }\end{array}$ & $-0.7(-1.2$ to -0.1$)$ & -0.22 & 0.011 \\
$\begin{array}{c}\text { Married } \\
\text { Self-reported } \\
\text { health }\end{array}$ & $-4.7(-8.5$ to -1.0$)$ & -0.19 & 0.013 \\
\hline
\end{tabular}

BMI, body mass index; HDL-C, high-density lipoprotein cholesterol; WC, waist circumference.
College of Radiology Guidelines, the 75th percentile for age and sex indicated an aggravating factor for CAD and high risk of clinical events in 2 to 5 years (Sara et al. 2014).

The results of a literature review show that the CAC score outperformed risk factors and other demographic variables for event prediction in nearly all studies, with a summary risk ratio for a combined coronary event (death, myocardial infarction, or revascularization) of 10.7 in asymptomatic individuals (Budoff 2001). In a multi-ethnic cohort of asymptomatic individuals selected from the MESA study, use of CAC plus traditional risk factors significantly improved the classification of risk for the prediction of coronary events using age greater than or equal to 45 years as the cutoff point for establishing CAC (Polonsky et al. 2010). In a study on coffee consumption and CAC in young and middle-aged asymptomatic adults apparently free of clinically evident cardiovascular disease, moderate coffee consumption was associated with a lower prevalence of subclinical coronary atherosclerosis as determined by the CAC score (Choi et al. 2015).

Hecht (2015), in a study on CAC scanning, states that $\mathrm{CAC}$ has not been incorporated into the mainstream of clinical cardiology and has been downgraded in the 2013 dyslipidemia guidelines. He reports that, although the benefits are very clear, including risk stratification higher than the initial risk, leading to a high reclassification index, economic feasibility and very low radiation exposure (similar to mammography), the main obstacles to using coronary artery tomography for CAC measurement are the lack of randomized clinical trials and the presence of incidentalomas. $\mathrm{He}$ also states that in future applications the examination could be combined with heart and lung investigations (Hecht 2015). In the UK National Institute for Health and Clinical Excellence practice guidelines, having a zero CAC score is currently used as a criterion for further investigations in 
patients presenting to emergency departments with chest pain (Latif et al. 2014).

The most notable finding in our cohort was the reduction in HDL-C levels. Therefore, because only one subject had detectable CAC on the followup scan, we investigated possible associations between change in HDL-C levels and the study variables. The Framingham study found that the relative risk of developing CAD in relation to the mean population risk increases from 1 to 4 when low-density lipoprotein cholesterol (LDL-C) levels raise from 130 to $190 \mathrm{mg} / \mathrm{dL}$ and decreases from 4 to 1 when HDL-C increases from 15 to $45 \mathrm{mg} / \mathrm{dL}$ (Castelli 1988). In our study, WC had the strongest association with variation in HDL-C levels, with participants who gained $1 \mathrm{~cm}$ in $\mathrm{WC}$ showing a mean reduction of $0.36 \mathrm{mg} / \mathrm{dL}$ in HDL-C.

The lowest HDL-C value $(23 \mathrm{mg} / \mathrm{dL})$ was found in the CAC-positive male participant, who also had a family history of early cardiovascular disease, a sedentary lifestyle, was obese and smoked. In a causal chain theoretical model, it is known that the more distal the exposure, the lower the strength of association with the outcome. However, if the data indicate that both low HDL-C and CAC are present, it can be inferred that there is a strong association with acute myocardial infarction (de Macedo and Faerstein 2017).

A limitation of the present study is that CAC scanning was included only in the 2016 evaluation. Therefore, we were unable to establish exactly when the CAC-positive participant developed CAC or investigate the characteristics related specifically to the transition from zero to nonzero CAC.

In conclusion, although the variations in cardiovascular risk factors in 1999, 2006 and 2016 were not associated with subclinical atherosclerosis according to CAC scores, the evidence from this study may stimulate discussion about protocols for new and broader studies of populations under 35 years of age with HDL-C levels below $25 \mathrm{mg} /$ $\mathrm{dL}$ and family histories of cardiovascular disease, associated with obesity, sedentary lifestyle and smoking.

\section{REFERENCES}

AGATSTON AS, JANOWITZ WR, HILDNER FJ, ZUSMER NR, VIAMONTE JR M AND DETRANO R. 1990. Quantification of coronary artery calcium using ultrafast computed tomography. J Am Coll Cardiol 15: 827-832.

ALLURI K ET AL. 2015. Distribution and burden of newly detected coronary artery calcium: Results from the MultiEthnic Study of Atherosclerosis. J Cardiovasc Comput Tomogr 9: 337-344.

AZEVEDO CF, ROCHITTE CE AND LIMA JAC. 2012. Coronary artery calcium score and coronary computed tomographic angiography for cardiovascular risk stratification. Arq Bras Cardiol 98: 559-568.

BUDOFF MJ. 2001. Prognostic value of coronary artery calcification. JCOM 8: 42-48.

CASTELLI WP. 1988. Cholesterol and lipids in the risk of coronary artery disease the Framingham Heart Study. Can J Cardiol 4(Suppl A): 5A-10A.

CHOI Y, CHANG Y, RYU S, CHO J, RAMPAL S, ZHANG Y, AHN J, LIMA JA, SHIN H AND GUALLAR E. 2015. Coffee consumption and coronary artery calcium in young and middle-aged asymptomatic adults. Heart 101: 686691.

DE MACEDO LET AND FAERSTEIN E. 2017. Cholesterol and prevention of atherosclerotic events: limits of a new frontier. Rev Saúde Públ 51: 1-7.

GO AS ET AL. 2014. Heart disease and stroke statistics 2014 update: a report from the American Heart Association. Circulation 129: e28-e292.

HAIR JF, ANDERSON RE, TATHAM RL AND BLACK WC. 1998. Variance Inflation Factor. In: Multivariate Data Analysis, New Jersey: Prentice Hall, p. 189-193.

HECHT HS. 2015. Coronary artery calcium scanning: past, present, and future. JACC Cardiovasc Imaging 8: 579-596.

LATIF MA, BUDOFF MJ AND NASIR K. 2014. Exploring the complementary role of CAC and coronary $\mathrm{CT}$ in the primary CVD prevention setting. Curr Cardiovasc Risk Rep 8: 1-10.

LEE CD, JACOBS JR DR, SCHREINER PJ, IRIBARREN C AND HANKINSON A. 2007. Abdominal obesity and coronary artery calcification in young adults: the Coronary Artery Risk Development in Young Adults (CARDIA) Study. Am J Clin Nutr 86: 48-54.

MENEGHELO RS, SANTOS RD, ALMEIDA B, HIDAL J, MARTINEZ T, MORON R, RAMIRES JAF AND NASRI F. 2003. Distribuição dos escores de cálcio coronariano determinados pela tomografia ultra-rápida em 2.253 homens brancos assintomáticos. Arq Bras Cardiol 81: $27-$ 31 . 
PITREZ FILHO MLS. 2000. Análise da prevalência de fatores de risco cardiovascular em adolescentes do município de Veranópolis (Master's thesis). Porto Alegre: Pontifícia Universidade Católica do Rio Grande do Sul/PUCRS. (Unpublished).

POLONSKY TS, MCCLELLAND RL, JORGENSEN NW, BILD DE, BURKE GL, GUERCI AD AND GREENLAND P. 2010. Coronary artery calcium score and risk classification for coronary heart disease prediction. JAMA 303: 1610-1616.

SANTANA JCB, PITREZ FILHO MLS, VARGAS LTR, HAUSCHILD JA, PINTO LA, PITREZ EH, BRUSCATO
NM, OLIVEIRA JR AND MORIGUCH E. 2012. Relação entre medidas antropométricas em adolescentes e fatores de risco cardiometabólicos em adultos jovens. Acta Pediatr Port 43: 225-232.

SARA L ET AL. 2014. II Diretriz de ressonância magnética e tomografia computadorizada cardiovascular da sociedade brasileira de cardiologia e do colégio brasileiro de radiologia. Arq Bras Cardiol 103(6 Supl. 3): 1-86.

XAVIER HT ET AL. 2013. V Diretriz brasileira de dislipidemias e prevenção da aterosclerose. Arq Bras Cardiol 101(4 Supl.1): 1-22. 